\title{
Malaria Parasitaemia and Changes in Follicle Stimulating Hormone and Luteinizing Hormone Levels of Adult Mice
}

\author{
Naiho Alexander Obidike, ${ }^{1, ~}$, Ebite Lilian Ozokor ${ }^{2}$, Ovuakporaye Simon Irikefe $^{1}$, \\ Gbagbeke Kelvin Obakore ${ }^{1}$, Kelechi Keneth Anachuna ${ }^{1}$ \\ ${ }^{1}$ Department of Human Physiology, Faculty of Basic Medical Sciences, College of Health Sciences, Delta State University, Abraka, Delta \\ State, Nigeria \\ ${ }^{2}$ Department of Anatomy, Faculty of Basic Medical Sciences, College of Health Sciences, Delta State University, Abraka, Delta State, \\ Nigeria
}

Email address:

osgiedeprof@yahoo.com (N. A. Obidike)

${ }^{*}$ Corresponding author

\section{To cite this article:}

Naiho Alexander Obidike, Ebite Lilian Ozokor, Ovuakporaye Simon Irikefe, Gbagbeke Kelvin Obakore, Kelechi Keneth Anachuna. Malaria Parasitaemia and Changes in Follicle Stimulating Hormone and Luteinizing Hormone Levels of Adult Mice. Advances in Applied Physiology. Vol. 5, No. 1, 2020, pp. 1-5. doi: 10.11648/j.aap.20200501.11

Received: February 19, 2020; Accepted: March 26, 2020; Published: April 14, 2020

\begin{abstract}
To understand the treatment of malaria, it is important to understand the effect of the administration of specific anti-malarials on various physiological variables. Current study investigated the effect (s) of the anti-malarial, coartem and co-administration of the antioxidant, Vitamin E on the levels of Luteinising and Follicle Stimulating Hormones [LH and FSH] of malaria parasite infected mice. Twenty-eight (28) adult mice were obtained, acclimatized for two (2) weeks and randomly selected into four (4) groups of seven (7) rats per group. Group 1 (Control) received standard mice diet and water ad libitum, while group 2 mice were infected with malaria (Plasmodium berghei) and left untreated. Groups 3 and 4 were inoculated with malaria (Plasmodium berghei); then treated with coartem and coartem + vitamin E respectively. After three (3) weeks of administration of test substance, the mice blood samples were obtained from mice (for each group) and assayed for serum FSH and LH levels. Statistical comparison was then conducted (using the student t-test) against those of control group to ascertain the effects of the changes due to coartem and/or antioxidant vitamin E co-administration to plasmodium berghei infected mice. Study found a statistically significant increase in serum LH levels of male mice after inoculation with plasmodium berghei. This decrease was noticed more even with coartem and antioxidant vitamin E co-administration, implicative of a possible effect in fecundity levels of infected male mice. The level of FSH was significantly increased in infected mice, but however showed a reversal following treatment with coartem and/or antioxidant vitamin E. The effects on reproductive hormones seen here may mirror the effects in man. More studies are needed to elucidate that.
\end{abstract}

Keywords: Coartem, Leutinizing Hormone, Follicle Stimulating Hormone

\section{Introduction}

Malaria is the most prevalent preventable tropical disease in the world today. It has affected human for over fifty thousand years, and may have been a human pathogen for the entire history of our species. In the tropical and subtropical regions, during the first half of the twentieth century, malaria affected every walk of life so much that its effects on developing economy been studied $[1,2]$ It is estimated to have affected about 3.4 million people in 92 countries of the world in 2019. There were about 219 million cases of malaria in 2017 causing 43500 deaths. [3]

Malaria is endemic in part of Asia, Africa, central and South America, Oceania, and certain Caribbean islands. It is endemic in Nigeria and it takes a heavy toll on our pregnant women and children. Nigeria accounted for $25 \%$ of cases of malaria worldwide in 2018 and accounted for $24 \%$ of global malaria deaths in 2018. [3] 
Follicle-stimulating hormone (FSH) is a gonadotropin, a glycoprotein polypeptide hormone. FSH is synthesized and secreted by the gonadotropic cells of the anterior pituitary gland, and regulates the development, growth, pubertal maturation, and reproductive processes of the body. FSH and luteinizing hormone $(\mathrm{LH})$ work together in the reproductive system.

FSH stimulates primary spermatocytes to undergo the first division of meiosis, to form secondary spermatocytes. It enhances the production of androgen-binding protein by the Sertoli cells of the testes. [4. 5]

Luteinizing hormone (LH) is released from the pituitary gland, and is controlled by pulses of gonadotropin-releasing hormone $(\mathrm{GnRH})$. It stimulates Leydig cell production of testosterone. It acts synergistically with FSH. LH acts upon the Leydig cells of the testis and is regulated by gonadotropin-releasing hormone $(\mathrm{GnRH})$. The Leydig cells produce testosterone (T) under the control of $\mathrm{LH}$, which regulates the expression of the enzyme $17 \beta$-hydroxysteroid dehydrogenase that is used to convert androstenedione, the hormone produced by the testes, to testosterone, an androgen that exerts both endocrine activity and intratesticular activity on spermatogenesis. $[5,6]$

Malaria causes severe disease. Severe malaria complications include cerebral malaria, miscarriages, febrile seizures, hypoglycaemia and others which can all lead to mortality. [7]

WHO recommends artemisinin-based combination therapies (ACTs) for the treatment of uncomplicated malaria caused by the $\mathrm{P}$. falciparum parasite. By combining two active ingredients with different mechanisms of action, ACTs are the most effective antimalarial medicines available today, but they certainly leave some adverse effect on the patients. $[7,8]$

Hormonal changes due to malaria has been studied and malaria chemotherapy has been associated with adverse effects on reproductive function. [9, 10] Antifertility effects of artemisinin in male rats has been reported. [11] We therefore undertook to study the effects of malaria parasitaemia and antimalaria chemotherapy on FSH and LH in male mice.

\section{Aim of Study}

The study aimed at investigating Malaria Parasitaemia and Changes in Follicle Stimulating Hormone and Luteinizing Hormone Levels. Specifically, the study;

i. Ascertained the changes in body weights in Malaria parasite infected mice.

ii. Determined the serum FSH and LH level of male mice infected with malaria parasitaemia.

iii. Determined the changes in serum FSH and LH levels of malaria infected, and treated mice

\section{Materials and Methods}

\subsection{Location of Study}

Study was conducted in the animal house of the college of
Health sciences, Department of Human Physiology, Delta State University, Abraka, Delta State.

\subsection{Study Design}

The study focussed on assessing the effect of Malaria parasitaemia on the follicle stimulating hormone and leutinizing hormone levels in male albino mice. Twenty-eight (28) mice were procured, acclimatized for two weeks, and then, divided into four (4) groups of seven (7) animals each as follows;

Groups 1 (control): Which received standard chow and water ad libitum.

Groups 2: Infected with malaria (Plasmodium berghei) and given only water and chow.

Groups 3: Infected with malaria (Plasmodium berghei) and treated with coartem solution only.

Groups 4: Infected with malaria (Plasmodium berghei) and treated with coartem and vitamin $\mathrm{E}$.

\subsection{Animal Procurement}

The study was carried out on 28 healthy adult male mice, which were procured from the breeding unit of animal house of Faculty of Basic Medical Sciences, Delta State University, Abraka, Delta State Nigeria. The handling of the animals was carried out in accordance with ethical guild lines for investigation and approved by local ethical committee for the care of and use of laboratory animals. The mice were house in isolated steel cages and kept under a 12 hours light and dark cycle at room temperature.

\subsection{Acclimatization}

After the purchase of these animal, they were kept in the cage for two weeks and fed with water and rat chow for proper adaptation to the environment, after which they were divided into control and experiment.

\section{Treatment of Mice}

\subsection{Preparation for Coartem Solution}

Coartem tablets were ground into powder form using a mortar. Thereafter, $1000 \mathrm{ml}$ of distilled water was measured with the aid of a graduated cylinder and $1 \mathrm{~g}$ of coartem powder was thereafter added into the distilled water and mixed thoroughly.

\subsection{Preparation for Anti-oxidant (Vitamin E) Solution}

About $0.2 \mathrm{ml}$ of distilled water was measured and added to $0.2 \mathrm{ml}$ of alcohol, $9.6 \mathrm{ml}$ of vitamin $\mathrm{E}$ was measured with the aid of $10 \mathrm{ml}$ syringe and added to the mixture of alcohol and water, and was a stored in a conical flask/crucible. The alcohol used here was to avoid the coagulation of the vitamin E (anti-oxidant) solution.

\subsection{Drug Administration}

Using a $1 \mathrm{ml}$ syringe, $5.7 \mathrm{mg} / \mathrm{kg}$ body weight of coartem 
solution was measured and administered to the infected mice orally. This was carried out in the morning and evening for 3 days respectively. Also using $1 \mathrm{ml}$ syringe, $20.8 \mathrm{mg} / \mathrm{kg}$ body weight of vitamin E. solution was measured and administered to the infected mice orally. This was carried out once a day, in a period of a two (2) day interval for vitamin $\mathrm{E}$ treatment.

\subsection{Sample Collection}

At the end of the treatment, the mice were anesthetized in a desiccator containing cotton wool soaked with chloroform. After they had attained deep anesthesia, they were brought out of the dessicator and laparotomy was carried out (by making $\mathrm{V}$-shape incision in the abdominal region with the aid of a surgical scissors) and the visceral organs were exposed, blood samples were obtained from the mice by cardiac puncture from the hepatic portal vein and hormonal assay was done immediately.

\section{Procedure for Hormonal Assay}

\subsection{Determined of Follicle Stimulating Hormone (FSH)}

Method:

Principle:

The FSH quantitative test is based on a solid phase enzyme-linked immunosorbent assay system utilizes a mouse monoclonal anti-a, FSH antibody for solid phase (microtite wells) immobilization and another mouse monoclonal antiFSH in the antibody-enzyme (horseradish peroxidase) conjugate solution. The test sample is allowed to react simultaneously with the antibodies, resulting in FSH molecules being sandwiched between the solid phase and enzyme-linked antibodies. After 45minutes incubation at room temperature, the wells are washed with water to remove unbound-labeled antibodies. A solution of TMB Reagent is added and incubated at room temperature for 20minutes, resulting in the development of a blue color which is changed to yellow and measured spectrophotometrically at $450 \mathrm{~nm}$. The concentration of FSH is directly proportional to the color intensity of the test sample.

Procedure:

The desired number of coated wells in the holder was secured. 50ul of standard, specimens, and controls were dispensed into appropriate wells. 100ul of enzyme conjugate Reagent was added into each well. This was mixed thoroughly for 30 minutes and was further incubated at room temperature (18-25c for 45 minutes. The incubation mixture was removed by flicking plate contents into each well into the waste container. 100ul of TBM reagent was dispensed into each well and mixed gently for 10seconds. The optical density was read at $450 \mathrm{~nm}$ with a microtiter plate reader within 15 minute.

Calculation of results;

The mean absorbance value (A450) for each set of reference standards, specimens, controls and patient samples were calculated. A standard curve was constructed by plotting the mean absorbance obtained from each reference standard against its concentration in $\mathrm{mlU} / \mathrm{ml}$ linear graph paper, with absorbance values on the vertical or $\mathrm{Y}$-axis and concentration on the horizontal or $\mathrm{X}$ axis. The mean absorbance value for each sample, determine the corresponding concentration of $\mathrm{FSH}$ in $\mathrm{mlU} / \mathrm{ml}$ from the standard curve.

\subsection{Determination of Luteinizing Hormone (LH)}

Method:

Principle:

In this test, the targeted antigen $\mathrm{LH}$ in the sample is immobilized through binding between the streptavidin coated onto the walls of the microplate and the biotin molecule that is part of the biotinylated monoclonal antibody added in the enzyme conjugate, together with another specific enzymeconjugated antibody, the target antigen and biotinylated antibody forms a sandwich complex on the walls of the microplate after a period of incubation. After a wash step that removes any unbound molecules, a substrate is added to react with the enzyme conjugated on the cold anti-body, a blue color develop during the incubation period. the intensity of the color is directly correlated to the concentration of the target antigen, LH in the serum sample. After the addition of the stop solution, the concentration of LH can be quantified using this correlation.

Ethical Clearance

Ethical clearance was obtained from the Research and Ethics Committee of the Faculty of Basic Medical Sciences, College of Health Sciences, Delta State University, Abraka, Delta State. All animals were treated in line with guidelines, stipulated by the National Institute for Health Guide on the Care and Use of Laboratory Animals (1985).

Statistical Analysis

Statistical significance of treatment effect (s) was analyzed with the students't-test, with values expressed as Mean \pm SEM (Standard Error of Mean). All of these were automated and achieved with the statistical package for social sciences (SPSS) version 20. Differences between means were considered at $\mathrm{p}<0.05$.

\section{Results}

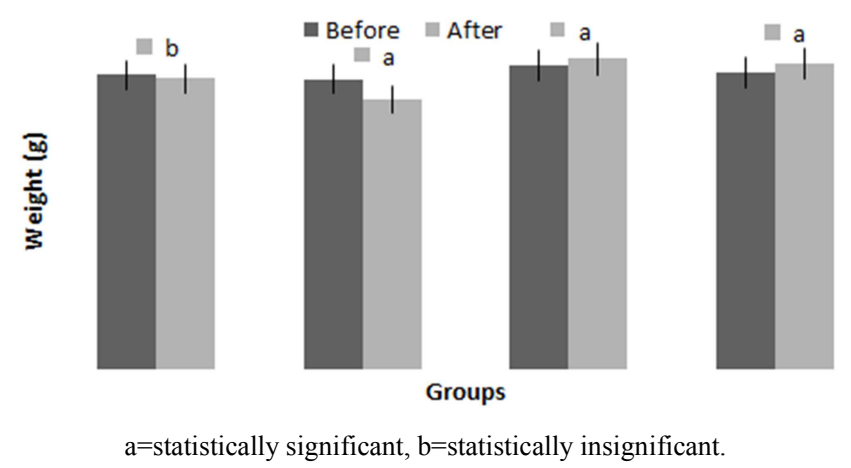

Figure 1. Changes in Body Weights before and after the experiment. 
Table 1. T-test Result of Weights Changes in Malaria Parasite Infected Mice.

\begin{tabular}{llllll}
\hline Groups & Before & After & t-cal & p-value & Remark \\
\hline 1 & 131.93 & 130.33 & 0.59 & 0.3012 & Insignificant \\
2 & 129.93 & 120.93 & 0.54 & 0.0026 & Significant \\
3 & 136.00 & 139.00 & 0.48 & 0.0054 & Significant \\
4 & 133.00 & 137.00 & 0.56 & 0.0006 & Significant \\
\hline
\end{tabular}

$\mathrm{P} \leq 0.05=$ statistically significant.

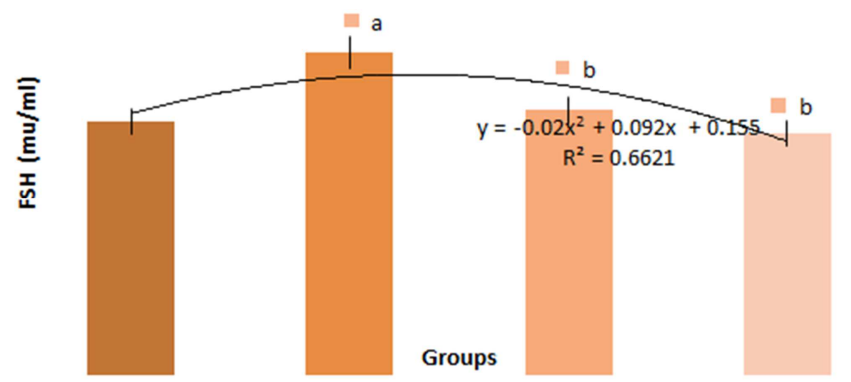

Figure 2. Changes in Follicle Stimulating Hormone (FSH) Levels in Malaria Parasite Infested Mice.

$\mathrm{a}=$ statistically significant increase $(\mathrm{p}<0.05), \mathrm{b}=$ statistically insignificant decrease $(\mathrm{p}<0.05)$ compared with control group.

Table 2. T-test Result of FSH Changes in Malaria Parasitaemia Infested Mice.

\begin{tabular}{llllll}
\hline Groups & Experimental & Control & t-cal & p-value & Remark \\
\hline 2 & $0.28 \pm 0.20$ & $0.22 \pm 0.11$ & 0.91 & 0.0211 & Significant \\
3 & $0.23 \pm 0.13$ & $0.22 \pm 0.11$ & 0.13 & 0.0100 & insignificant \\
4 & $0.21 \pm 0.10$ & $0.22 \pm 0.11$ & 0.11 & 0.0021 & insignificant \\
\hline
\end{tabular}

$\mathrm{P} \leq 0.05=$ statistically significant.

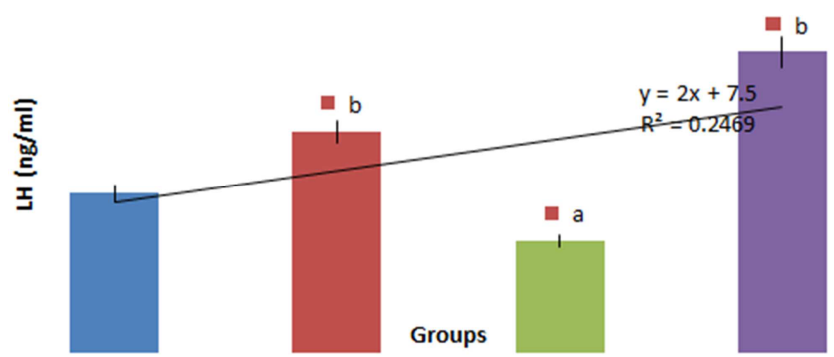

Figure 3. Changes in Luteinising Hormone Levels in Malaria Parasitaemia Infested Mice.

$\mathrm{a}=$ statistically significant decrease $(\mathrm{p}<0.05), \mathrm{b}=$ significant increase compared with control group.

Table 3. T-test Result of Luteinising Hormone Changes in Malaria Parasitaemia Infested Mice.

\begin{tabular}{llllll}
\hline Groups & Experimental & Control & t-cal & p-value & Remark \\
\hline 2 & $15.00 \pm 1.21$ & $10.00 \pm 1.11$ & 0.13 & 0.0360 & Significant \\
3 & $7.00 \pm 0.30$ & $10.00 \pm 1.11$ & 0.22 & 0.7020 & Insignificant \\
4 & $19.00 \pm 1.62$ & $10.00 \pm 1.11$ & 0.14 & 0.0114 & Significant \\
\hline
\end{tabular}

$\mathrm{P} \leq 0.05=$ statistically significant increase compared to control.

\section{Discussion}

The study assessed the effect of malaria parasitaemia on FSH and luteinizing hormone levels. The different reproductive hormone changes due to malaria infection and treatment with coartem and vitamin $\mathrm{E}$ were investigated in this study, especially on FSH and LH levels of male mice.

The results from this study showed a significant weight reduction $(\mathrm{p}<0.05)$ in infected mice by the end of the experimental period (129.93g -120.93g). This weight loss of about 9 grams on the average is much higher than what was observed with the control group $(1.6 \mathrm{~g})$. This is in agreement of other studies which found progressive and significant weight loss in plasmodium berghei infected mice ${ }^{12}$. The weight losing effect of malaria parasite infection of the mice was apparently reversed with treatment of the malaria with coartem. The coartem treatment group and the coartem plus vitamin $\mathrm{E}$ treatment group gained weight significantly (3g and $4 \mathrm{~g}$ respectively). This observation suggests a nutrition improving effect of treatment of malaria with effective medication.

The major change in follicular stimulating hormone (FSH) was seen in the infected group. This significant increase in FSH is remarkable especially since these are male mice. The FSH is important for the meiotic division in spermatogenesis ${ }^{13}$. This suggests a rise in sperm production occasioned by malaria in mice. This finding is not in agreement with a study at Ibadan, Nigeria which found no significant difference in FSH levels in adult wistar rats treated with ACTs (artemether / lumefantrine and artesunate / amodiaquine). [13] In this study, there was no significant difference in FSH levels between controls and mice treated with either coartem or coartem plus vitamin E. This suggests a reversal of the spike seen in infected mice thereby raising the possibility that the increase in FSH levels seen in infected mice may be reactionary rather than physiological.

The most riveting observation of this study is the changes observed in the levels of luteinizing hormone in the experimental mice. Malaria parasite infection and treatment of malaria all led to increase in luteinizing hormone levels. However, the increase observed in the coartem treatment group was not significant, the infected group and the coadminstration group showed significant increases. Luteinizing hormone is very important for the secretion of testosterone ${ }^{13}$. This means that the testosterone levels of all infected mice was elevated irrespective of whether they were undergoing treatment or not. This finding is corroborated by Adejuwon and Adejuwon and Ojezele and colleagues ${ }^{14,15}$. It is however contrary to the finding by Raji et al., ${ }^{10}$ who reported a reduction in testosterone levels of parasitized mice.

\section{Conclusion}

This study has yet again provided evidence that malaria parasitaemia does have effects on the reproductive function of male rats and this may be so in humans. More studies are required to elucidate and characterize these effects so as to continue to protect the continuity of the human species. 


\section{References}

[1] Ricca F (2012). Social implication of malaria and their relationship with poverty. Mediterr J Haematol Infect Dis 4 (1).

[2] Berman, J. (2001). The ears of the hippotamus; manifestations, determinants and estimate of the malaria burden. Am. J. Trop. Med. Hyg; 64 (1-2): 1-11.

[3] World Health Organisation. World Malaria Report 2019. Geneva. 2019. www.who.int/malaria/publications/worldmalaria-report-2019/en/.

[4] Marshall, J. C (1975) Clinic in Endocrinol Metabolism. Investigative procedures clinc. Endocrimnol. Metab. 3: 545567.

[5] Boulpaep EL, Boron WF. Medical physiology: a cellular and molecular approach. Philadelphia, Saunders/elservier; 2005: $1319 \mathrm{p}$.

[6] Pitteloud N, Dwyer AA, DeCruz S, Lee H, Boepple PA, Crowley Jr WF, Hayes FJ. Inhibition of luteinizing hormone secretion by testosterone in men requires aromatization for its pituitary but not its hypothalamic effects: evidence from the tandem study of normal and gonadotropin-releasing hormonedeficient men. J Clin Endocrinol Metab 2008; 93 (7), 2686-92.

[7] Davidson R, Brent A, Seale A. Oxford Handbook of Tropical Medicine. UK, Oxford University Press, 2014; 34-67.

[8] World Health Organization (WHO) (2001). Antimalaria drugs combination therapy. Report of a WHO technical consultation. Document WHO/CDS/RBM/2001.35. Geneva.

[9] Okanlawon AO, Ashiru OA. Sterological estimation of seminiferous tubules dysfunction in chloroquine treated rats. Afr J Med Sci 1998; 27: 101-106.

[10] Raji Y, Akinsomisoye OS, Azeez MO. Impact of malaria parasite on reproductive indices of male mice. Reprod Med Biol 2006 sept; 5 (3): 201-210.

[11] Raji Y, Osonuga IO, Akinsomisoye OS, Osonuga OA, Mewoyeka OO. Gonadotoxicity evaluation of oral artemisinin derivative in male rats. J. Med Sci 2005; 5: 303-306.

[12] Basir R, Fazalul Rahiman SS, Hasballah K, Chong WC, Talib $\mathrm{H}$, Yam MF. Plasmodium berghei ANKA infection in ICR mice as a model of cerebral malaria. Iran J. Parasitol 2012; 7 (40): 62-74.

[13] Samuel SA, Ayobami D, Jane AE. Comparative effects of commonly used artemisinin-based combination therapies (ACTs) on reproductive parameters in male wistar rats. MOJ Bioequiv Availab 2008; 5 (2): 122-128.

[14] Adejuwon CA, Adejuwon AO. Serum steroids in mice infected with Plasmodium berghei berghei. J Med Sci 2005; 5 (3): $212-215$.

[15] Ojezele MO. Igbe I, Okhuarobo A. Reproductive indices in malaria infested mice treated with antimalarials, Phylanthus amarus combined with itamins. Bull Fac Pharm Cairo Univ 2018; 56 (2): 179-184. 